\title{
Composição físico-química e compostos bioativos do extrato aquoso de amendoim sem pele e enriquecido com pele
}

\author{
Physical chemical composition and bioactive compounds of \\ aqueous extract of peanuts without skin and enriched with \\ peanut skin
}

Thárcia Kiara Beserra de Oliveira1 (1D), Francisco de Assis Cardoso Almeida', Josivanda Palmeira Gomes ${ }^{1}$ (D), Amélia Ruth Nascimento Lima ${ }^{2}$, Inácio de Barros Melo Neto ${ }^{3}$, Paulo Roberto da Silva Júnior ${ }^{4}$, Katharina Rodrigues de Lima Porto Ramos ${ }^{5}$

\author{
${ }^{1}$ Universidade Federal de Campina Grande (UFCG), Centro de Tecnologia e Recursos Naturais, Campina \\ Grande/PB - Brasil \\ ${ }^{2}$ Centro Universitário UNIFACISA, Departamento de Nutrição, Campina Grande//PB - Brasil \\ ${ }^{3}$ Faculdade de Medicina de Olinda (FMO), Olinda/PE - Brasil \\ ${ }^{4}$ Centro Universitário UNIFACISA, Departamento de Medicina, Campina Grande/PB - Brasil \\ ${ }^{5}$ Universidade Estadual da Paraíba (UEPB), Centro de Ciências Biológicas e da Saúde, Campina Grande/PB - \\ Brasil
}

*Corresponding Author: Thárcia Kiara Beserra de Oliveira, Universidade Federal de Campina Grande (UFCG), Centro de Tecnologia e Recursos Naturais, Av. Aprígio Veloso, 882, Bairro Universitário, CEP: 58429-900,

Campina Grande/PB - Brasil, e-mail: tharcia_kiara@hotmail.com

Cite as: Oliveira, T. K. B., Almeida, F. A. C., Gomes, J. P., Lima, A. R. N., Melo Neto, I. B. M., Silva Júnior, P. R., \& Ramos, K. R. L. P. (2021). Physical chemical composition and bioactive compounds of aqueous extract of peanuts without skin and enriched with peanut skin. Brazilian Journal of Food Technology, 24, e2020166. https://doi.org/10.1590/1981-6723.16620

\begin{abstract}
Resumo
Objetivou-se realizar a caracterização físico-química e dos compostos bioativos do extrato aquoso de amendoim sem pele e acrescido de $1 \%$ de pele. Os extratos aquosos de amendoim sem e com pele foram caracterizados quanto aos parâmetros: umidade, extrato seco total, cinzas, lipídios, proteínas, teor de sólidos solúveis, acidez titulável, pH, carboidrato e fibras totais, além de compostos fenólicos e flavonoides. Os percentuais de umidade encontrados foram elevados em todas as amostras, resultante de sua base de extrato aquoso produzido na proporção 1:8 (amendoimá́gua). Observou-se que os extratos aquosos de amendoim sem pele e acrescido de $1 \%$ de pele não apresentaram diferença significativa entre si para os parâmetros de pH, como também para sólidos solúveis totais, lipídios e carboidratos. No entanto, a acidez, proteínas, fibras e cinzas apresentaram diferença estatística. Na determinação de compostos fenólicos, notou-se que o extrato aquoso de amendoim com pele apresentou uma quantidade maior quando comparado ao sem pele. Quanto aos flavonoides, a maior quantidade também foi encontrada na amostra com pele, apresentando uma diferença média de 2,52 $\mu \mathrm{g} / 100 \mathrm{~g}$ base úmida. Os extratos aquosos de amendoim com e sem pele mostraram ser uma valiosa alternativa para um melhor aproveitamento do amendoim, proporcionando à população um produto nutricional. A bebida acrescida de $1 \%$ de pele enriqueceu o produto quanto ao potencial antioxidante devido às suas maiores concentrações de compostos fenólicos totais e flavonoides.
\end{abstract}

Palavras-chave: Polifenóis; Alimentos; Flavonoides; Leite vegetal; Proteínas; Lipídios. 


\begin{abstract}
The objective of this work was to carry out the physical-chemical characterization and bioactive compounds of aqueous extract of peanuts without skin and with addition of $1 \%$ of skin. The aqueous extracts of peanuts without and with skin were characterized according to the parameters: moisture, total dry extract, ash, lipids, proteins, soluble solids content, titratable acidity, $\mathrm{pH}$, carbohydrates and total fibers, in addition to phenolic and flavonoid compounds. The percentages of moisture found were high in all samples, resulting from its base of aqueous extract produced in the proportion 1:8 (peanut:water). It was observed that the aqueous extracts of peanuts without skin and the addition of $1 \%$ of skin did not present significant difference between them for the $\mathrm{pH}$ parameters, as well as for total soluble solids, lipids and carbohydrates. However, acidity, proteins, fibers and ash presented a statistical difference. In the determination of phenolic compounds, it was noted that the aqueous extract of peanuts with skin presented a larger amount when compared to those without skin. As for flavonoids, the largest amount was also found in the skin sample, obtaining an average difference of $2.52 \mu \mathrm{g} / 100 \mathrm{~g}$ wet basis. The aqueous extract of peanuts with and without skin proved to be a valuable alternative for a better use of peanuts, providing the population with a nutritional product. The beverage added with $1 \%$ of skin enriches the product in terms of its antioxidant potential, due to its greater concentrations of phenolic compounds and flavonoids.
\end{abstract}

Keywords: Polyphenols; Food; Flavonoids; Plant milk; Proteins; Lipids.

\title{
1 Introdução
}

A estreita relação entre dieta e saúde, somada ao amplo interesse da população em consumir alimentos saudáveis, tem levado a indústria de alimentos ao desenvolvimento de novos produtos, com grande destaque aos alimentos funcionais (Abreu et al., 2007; Fabiansson, 2014; Shin et al., 2015).

Um forte aliado à saúde é o amendoim, que se destaca por conter altos níveis de vitaminas e minerais, bem como as chamadas "gorduras boas", que são fundamentais para a manutenção da saúde. Este alimento possui uma alta concentração de polifenóis, os quais atuam como antioxidantes e reduzem a inflamação das artérias coronárias. Além disso, o amendoim contém uma quantidade considerável da coenzima Q10, nutriente este que fortalece o coração e o protege em condições de redução do fornecimento de oxigênio (Tedesco et al., 2017).

As partes comestíveis do amendoim consistem na amêndoa e na pele protetora. A pele possui uma cor vermelho-rosa de gosto adstringente, e é normalmente removida antes do consumo. No entanto, a pele do amendoim é rica em compostos fenólicos, fibras dietéticas e outros compostos que são promotores de saúde. Os compostos fenólicos concentram-se tipicamente nas camadas exteriores das plantas, tais como a casca e camadas protetoras (Yu et al., 2006; Anderson et al., 2009).

A pele de amendoim não desengordurada é uma rica fonte de ácidos fenólicos, como proantocianidinas, flavonoides e resveratrol. Por ser um subproduto na indústria de amendoim, pode atuar como uma fonte de baixo custo de compostos fenólicos, os quais são compostos que atuam na promoção da saúde (Yu et al., 2006).

Produtos à base de amendoim estão cada vez mais presentes de forma direta ou indireta na alimentação humana. Dentre o grande número de produtos derivados do amendoim está o extrato aquoso de amendoim, ou "leite de amendoim". Esse extrato vem sendo destacado por ser um alimento de fácil acesso e ampla riqueza nutricional, além de possuir um sabor agradável, o que torna o produto com boa aceitação para as pessoas que apreciam amendoim. A elaboração desse extrato é realizada de forma simples e rápida, em que uma pequena quantidade de grãos é triturada com água, filtrada e branqueada (Alves \& Almeida, 2016).

$\mathrm{O}$ extrato aquoso de amendoim possui 2,46\%/100 g de proteína e 3,68\%/100 g de ácidos graxos monoinsaturados, uma quantidade apreciável quando comparado com outras bebidas elaboradas por grãos de soja (Alves \& Almeida, 2016). Os ácidos graxos monoinsaturados contribuem no aumento da captação do 
colesterol de baixo peso molecular (LDL) pelo fígado e na elevação dos valores séricos de colesterol de alto peso molecular (HDL) (Oliveira et al., 2016).

Tendo em vista a importância do conhecimento sobre o tema, e sendo o extrato aquoso de amendoim e a pele do amendoim ambos um produto novo, que requerem estudos quanto a sua caracterização, o trabalho teve como objetivo realizar a caracterização físico-química e nutricional do extrato aquoso de amendoim sem pele e acrescido de $1 \%$ de pele.

\section{Material e métodos}

O experimento foi realizado no Laboratório de Armazenamento e Processamento de Produtos Agrícolas do Departamento de Engenharia Agrícola da Universidade Federal de Campina Grande e no laboratório de Bromatologia do Centro Universitário Unifacisa.

O amendoim (Arachis hypogaea L.) foi obtido na Feira Central de Campina Grande, PB, e seguindo a metodologia empregada por Alves \& Almeida (2016), foi descascado e separado em duas partes: grão de amendoim sem pele e grão de amendoim acrescentado com pele do amendoim. O extrato da polpa foi preparado na proporção $1: 8$, de modo a obter uma concentração final de $1,25 \mathrm{mg} / \mathrm{mL}$, e o segundo extrato foi preparado de forma semelhante, porém no processo de extração foi acrescentado $1 \%$ de pele do amendoim no volume total $(\% \mathrm{p} / \mathrm{v})$. A extração foi realizada por turbolização, utilizando um liquidificador com lâminas, com rotação de $6000 \mathrm{rpm} / \mathrm{min}$, durante 3 minutos. O solvente utilizado foi água filtrada, em que para cada $12,5 \mathrm{~g}$ de amendoim foram inseridos $100 \mathrm{~mL}$ de água. Em seguida, o extrato foi submetido a filtração.

Os extratos aquosos de amendoim sem e com pele (EAAsp e EAAcp) foram caracterizados quanto aos parâmetros: Umidade (\%), extrato seco total (EST) (\%), cinzas (\%), lipídios (\%), proteínas (\%), teor de sólidos solúveis (SST) $\left(\right.$ Brix $\left.^{\circ}\right)$, acidez titulável (AT) $\left({ }^{\circ} \mathrm{D}\right), \mathrm{pH}$, carboidratos (\%) e fibras totais (\%), além de compostos fenólicos e flavonoides.

As análises dos teores de umidade e extrato seco total foram determinadas pelo método de secagem das amostras em estufa a $105 \pm 3{ }^{\circ} \mathrm{C}$ até peso constante; $\mathrm{O}$ pH foi determinado pelo método potenciométrico, com medidor digital modelo TEC-2, do fabricante Tecnal ${ }^{\circledR}$ calibrado com soluções tampão de pH 4,0 e 7,0.

A acidez foi realizada pelo método titulométrico, que se baseia na neutralização dos íons $\mathrm{H}+$ com a solução de hidróxido de sódio $(\mathrm{NaOH})$ 0,1 N. Os sólidos solúveis foram determinados através de leitura direta da amostra em refratômetro portátil, modelo RT-32 (escala de 0 a $32{ }^{\circ}$ Brix), colocando-se uma gota da solução no prisma e realizando a leitura direta com correção da temperatura feita através de tabela proposta pelo Instituto Adolfo Lutz (2008).

O teor de proteína bruta foi quantificado pelo método Micro-Kjeldahl, que consiste na determinação do nitrogênio total. Para converter o resultado em proteína, foi utilizado o fator de correção 5,30\% (Instituto Adolfo Lutz, 2008).

A quantidade de lipídios foi determinada pelo método de Bligh \& Dyer (1959). Foram pesados 2 g da amostra em pote de vidro hermeticamente fechado, adicionando-se uma mistura de solvente constituído de $10 \mathrm{~mL}$ de clorofórmio e $20 \mathrm{~mL}$ de metanol em agitador magnético a $700 \mathrm{rpm}$ por $30 \mathrm{~min}$. Após completa homogeneização, foram adicionados $10 \mathrm{~mL}$ de clorofórmio e $10 \mathrm{~mL}$ da solução de sulfato de sódio a 1,5\%, seguido de agitação por 2 min.

A solução com a amostra foi transferida para um funil de separação para formação do sistema bifásico. A camada inferior, rica em clorofórmio contendo os lipídios, foi removida e transferidos $5 \mathrm{~mL}$ para um becker de $50 \mathrm{~mL}$ previamente tarado. Em seguida foram levados para a estufa a $80^{\circ} \mathrm{C}$ até evaporação do solvente (30-40 min). Após as amostras resfriadas em dissecador e pesadas em balança analítica, foi calculado o percentual de lipídios pela Equação 1:

$\%$ Lipidio $=\left(\frac{P \cdot 4}{P A}\right) 100$ 
Onde: P - peso dos lipídios contidos em $5 \mathrm{~mL}$, g e PA - peso da amostra, $\mathrm{g}$.

Os valores de carboidrato foram determinados por diferença pela Equação 2:

$C T=100-(\%$ Umidade $+\%$ Proteina $+\%$ Cinzas $)$

O teor de fibras nos extratos foi determinado pelo método de filtragem pelo sistema de vácuo com kitassato. As cinzas foram determinadas através da incineração da amostra em mufla aquecida a $550{ }^{\circ} \mathrm{C}$, até a obtenção de um resíduo isento de carvão, com coloração branca acinzentada (Instituto Adolfo Lutz, 2008).

Os compostos fenólicos totais foram determinados de acordo com a metodologia adaptada de Chandra \& Gonzalez de Mejia (2004), em que uma solução do extrato em água deionizada, com concentração conhecida, foi posta em contato com o reagente Folin-Ciocalteu (1:1). Após 2 min foi utilizado o carbonato de sódio (20\%) como segundo reagente. A absorbância da amostra foi requerida no comprimento de onda de $750 \mathrm{~nm}$. O padrão utilizado para a curva de calibração foi o ácido gálico.

Para a determinação de flavonoides totais, seguiu-se a metodologia de Francis (1982) utilizando-se cerca de 0,5 g de amostra com $20 \mathrm{~mL}$ de etanol: $\mathrm{HCl}(1,5 \mathrm{~N})$ na proporção 85:15 em ambiente escuro, e deixados em repouso por 24 horas na geladeira. As amostras foram filtradas em papel de filtro e as leituras realizadas em espectrofotômetro a $374 \mathrm{~nm}$.

Os resultados das análises foram submetidos a tratamento estatístico por meio de delineamento inteiramente casualizado com teste de comparação de médias, utilizando-se o software Assistat versão 7.7 beta (Silva \& Azevedo, 2009).

\section{Resultados e discussão}

Na Tabela 1 estão apresentados os valores médios da caracterização físico-química dos extratos sem e com pele de amendoim. Os percentuais de umidade encontrados foram elevados em todas as amostras, resultante de sua base de extrato aquoso produzido na proporção 1:8 (amendoim:água). Apesar do acréscimo de 1\% de pele na formulação EAAcp, não houve diferença significativa entre as formulações.

Assim como verificado em Alves \& Almeida (2016), ao elaborar e caracterizar extrato aquoso de amendoim em diferentes formulações, os pesquisadores obtiveram teor de umidade médio de $90,3 \%$ para a formulação 1:8, corroborando Oliveira et al. (2014), que obtiveram valor médio de 91,5\% de umidade para o extrato sem pele. A bebida acrescida de $1 \%$ de pele obteve valores menores de umidade quando comparado com o EAAsp (1,3\%). Essa discreta diminuição se justifica pelo acréscimo da pele de amendoim na formulação da bebida.

Tabela 1. Valores das caracterizações físico-químicas dos extratos aquosos de amendoim sem e com pele.

\begin{tabular}{ccc}
\hline \multirow{2}{*}{ Componente } & \multicolumn{2}{c}{ Extrato Aquoso de Amendoim } \\
\cline { 2 - 3 } & EAAsp & EAAcp \\
\hline Umidade (\%) & $89,8 \pm 0,15^{\mathrm{a}}$ & $88,5 \pm 0,50^{\mathrm{a}}$ \\
\hline EST (\%) & $10,2 \pm 0,04^{\mathrm{a}}$ & $11,5 \pm 0,11^{\mathrm{a}}$ \\
\hline $\mathrm{pH}$ & $6,83 \pm 0,26$ & $6,74 \pm 0,03$ \\
\hline Acidez titulável ( $\left.{ }^{\circ} \mathrm{D}\right)$ & $0,50 \pm 0,01^{\mathrm{b}}$ & $1,54 \pm 0,16^{\mathrm{a}}$ \\
\hline SST (Brix $\left.{ }^{\mathrm{b}}\right)$ & $5,16 \pm 0,15^{\mathrm{a}}$ & $5,36 \pm 0,30^{\mathrm{a}}$ \\
\hline Proteína (N x 5,30) (\%) & $4,05 \pm 0,02^{\mathrm{b}}$ & $4,36 \pm 0,35^{\mathrm{a}}$ \\
\hline Lipídios (\%) & $3,47 \pm 0,15^{\mathrm{a}}$ & $3,66 \pm 0,10^{\mathrm{a}}$ \\
\hline Carboidratos (\%) & $1,46 \pm 0,25^{\mathrm{a}}$ & $1,25 \pm 0,12^{\mathrm{a}}$ \\
\hline Fibras totais (\%) & $0,60 \pm 0,02^{\mathrm{b}}$ & $1,10 \pm 0,02^{\mathrm{a}}$ \\
\hline Cinzas (\%) & $0,49 \pm 0,01^{\mathrm{b}}$ & $1,44 \pm 0,24^{\mathrm{a}}$
\end{tabular}

Médias seguidas pela mesma letra, na linha, não diferem estatisticamente entre si. Foi aplicado o Teste de Tukey ao nível de 5\% de probabilidade. Todas as análises foram realizadas em triplicata. EAAsp $=$ sem pele. EAAcp $=$ Extrato aquoso de amendoim com pele. EST $=$ Extrato seco total; $\mathrm{N}=$ nitrogênio; $\mathrm{pH}=$ Potencial hidrogeniônico; $\mathrm{SST}=$ Teor de sólidos solúveis. 
Foi observado que os extratos aquosos de amendoim com e sem pele não apresentaram diferença significativa entre si para os parâmetros de pH. Aroma, sabor, textura e estabilidade dos alimentos são elementos que sofrem ação do $\mathrm{pH}$ na manutenção de um produto. Valores de $\mathrm{pH}$ inferiores a 4 podem interferir no teor proteico devido à desnaturação das moléculas de proteína. Por outro lado, concentrações superiores a 4,5 influenciam no palato e aceleram o processo de deterioração, decorrente da não resistência contra microrganismos patogênicos e deteriorantes, prejudicando a conservação do produto final (Garcia Motta et al., 2017). Diante de valores elevados encontrados nos extratos, é necessária atenção em sua conservação e armazenamento.

Disparidade foi encontrada para acidez. A determinação de acidez pode fornecer uma resposta valiosa na apreciação do estado de conservação de um produto alimentício. Podemos observar nesse estudo valores superiores para o extrato com pele, sendo estas características favoráveis no armazenamento, por dificultarem o desenvolvimento de microrganismos deteriorantes. A legislação brasileira para bebidas vegetais recomenda uma acidez total inferior a 3\%, com isso, os resultados encontrados para as duas formulações estão de acordo com as normas vigentes (Instituto Adolfo Lutz, 2008).

Considerando que o teor de sólidos solúveis totais (SST) de um alimento está relacionado à concentração de açúcares, as amostras apresentaram percentuais superiores a 5\%, significando teor de sacarose mínimo para as bebidas analisadas. O SST encontra-se diretamente proporcional à quantidade de açúcar presente na bebida, onde $1^{\circ}$ Brix equivale aproximadamente a $1 \mathrm{~g}$ de sólidos (sacarose) dissolvidos em $100 \mathrm{~mL}$ do produto final.

A pesquisa com extrato aquoso de amendoim apresentou medidas de 5,16 e 5,36 ${ }^{\circ}$ Brix para as formulações sem e com pele respectivamente. Estes achados são justificados, pois não houve adição de açúcar no preparo da bebida. Os resultados são considerados favoráveis para produto aquosos, uma vez que a adição de água no produto tem efeito sobre a concentração de açúcar obtida durante as formulações.

O percentual de proteína para o EAAcp $(4,36 \%)$ foi maior, em valor absoluto, em comparação ao encontrado no EAAsp (4,05\%). Estes resultados são superiores aos encontrados por Pretti \& Carvalho (2012) para extrato aquoso de amendoim $(3,41 \%)$ e, aos determinados por Maia et al. (2006), para extrato aquoso de soja (3,18\%). Duong et al. (2016) caracterizaram as proteínas no extrato de semente de uva (GSE), extrato de chá verde (GTE) e extrato de pele de amendoim (PE). Tendo estes observado um valor mais elevado em GSE (46 g/kg), seguido por PE (10 g/ $\mathrm{kg})$ e GTE $(9 \mathrm{~g} / \mathrm{kg})$. Estes resultados indicam valores significativos de proteína encontrados na pele do amendoim.

Para as análises de gordura, os extratos de amendoim apresentam similaridades nos percentuais de lipídios, com 3,47\% para extrato sem pele e 3,66\% para extrato com adição de pele. Deve-se ressaltar que, em qualquer formulação do extrato aquoso com ou sem pele, a gordura a ser ingerida apresenta uma composição rica em ácido graxo insaturado, tornando-o importante do ponto de vista nutricional. Segundo Oliveira et al. (2016), os ácidos graxos contribuem para diminuir a oxidação lipídica, reduzindo a dislipidemia.

Quanto aos valores de carboidratos, observam-se valores similares para as duas formulações $1,46 \pm 0,25$ e 1,25 $\pm 0,12 \mathrm{~g} / 100 \mathrm{~g}$ com uma menor quantidade de carboidrato para formulação acrescida com pele. Devese considerar que, do ponto de vista econômico, tende-se um interesse no aumento centesimal dos alimentos. Resultado superior foi reportado por Alves et al. (2016), que caracterizaram o extrato de amendoim em diferentes formulações, encontrando $3,46 \%$ de carboidrato (1:8). Porém, nossos resultados foram similares na formulação de 1:10 (1,86\% carboidrato).

As bebidas elaboradas com amendoim apresentaram valores de fibras alimentares totais inferiores quando comparados aos teores proporcionais às matérias-primas de origem, o que já era esperado diante da quantidade de água adicionada no preparo das duas formulações. De acordo com a tabela nutricional, o amendoim possui $8 \mathrm{~g} / 100 \mathrm{~g}$ de fibras alimentares totais, sendo $0,8 \mathrm{~g}$ de fibras solúveis. Encontraram-se na bebida com pele valores superiores $(1,1 \%)$ de fibras quando comparados com o EAAsp $(0,6 \%)$, sendo justificados pelo acréscimo de pele ao produto. Ambos os valores foram superiores aos encontrados no extrato aquoso de soja, sendo 0,4\% (Universidade Estadual de Campinas, 2011). 
As quantidades de cinzas para os extratos sem pele e com pele foram, respectivamente, $0,49 \%$ e 1,44\%. Os valores obtidos foram superiores aos encontrados por Pretti \& Carvalho (2012), onde, em seu estudo, com a mesma formulação de extrato sem pele, o valor para cinzas foi de $0,2 \%$. Os resultados também foram superiores aos encontrados por Alves et al. (2016), que obtiveram o valor de 0,12\% e 0,19\% para as formulações 1:8 e 1:6.

Os valores superiores de cinzas encontrados na formulação com pele são justificados pelo acréscimo do material. Tal fato também resulta em ganho nutricional, uma vez que se encontram minerais em sua pele (Munekata et al., 2016). Bicudo et al. (2012) estudaram uma bebida fermentada de extrato hidrossolúvel de quinoa e apresentou teor de cinzas de $0,36 \%$, sendo inferior ao nosso estudo. Krumreich et al. (2013) relatam que o teor de cinzas em uma amostra alimentícia representa o conteúdo total de minerais, podendo ser utilizado como medida geral da qualidade.

Na Tabela 2 é possível observar as concentrações de alguns metabólitos presentes no extrato aquoso de amendoim nas duas formulações. Na determinação de compostos fenólicos, notou-se que o EAAcp obteve uma quantidade maior quando comparado ao sem pele. Esse resultado está relacionado ao acréscimo da pele no extrato, que o tornou mais rico em compostos fenólicos, corroborando o estudo realizado por Attree et al. (2015), em que foram observadas concentrações significantes de antocianidinas no extrato de amendoim.

Tabela 2. Valores de compostos fenólicos totais e flavonoides em base úmida presentes nos extratos aquosos de amendoim com e sem pele.

\begin{tabular}{ccc}
\hline Amostras & Compostos Fenólicos Totais $(\mathbf{m g}$ EAG/g) & Flavonoides $(\boldsymbol{\mu g} / \mathbf{~ 1 0 0 ~ g ~ b a s e ~ u ́ m i d a ) ~}$ \\
\hline EAAsp & $3,3 \pm 0,06^{\mathrm{b}}$ & $1,78 \pm 0,01^{\mathrm{b}}$ \\
\hline EAAcp & $5,7 \pm 0,02^{\mathrm{a}}$ & $4,30 \pm 0,01^{\mathrm{a}}$ \\
\hline CV (\%) & 27,63 & 21,37 \\
\hline DMS (\%) & 0,039 & 0,024 \\
\hline
\end{tabular}

Médias seguidas pela mesma letra, na coluna, não diferem estatisticamente entre si pelo teste de Tukey $(p \leq 0,05)$. EAG $=$ Equivalentes de ácido gálico; EAAsp = Extrato aquoso de amendoim sem pele; EAAcp = Extrato aquoso de amendoim com pele; $\mathrm{CV}=\mathrm{Coeficiente} \mathrm{de} \mathrm{variação;}$ DMS = Desvio médio simples.

Para o Extrato Aquoso sem pele foram encontrados valores menores quando comparado à formulação EAAcp, demonstrando um alto potencial de polifenóis para o extrato enriquecido com pele. Este resultado é importante, uma vez que os organismos vegetais possuem um grande arsenal de vias metabólicas para produção de substâncias. Estes metabólitos são produzidos de acordo com a necessidade de cada organismo vegetal e são bastante estudados por suas propriedades medicinais (Larrauri et al., 2016).

Além disso, demonstrou-se que os polifenóis do amendoim são capazes de reduzir os níveis plasmáticos de ácidos graxos em ratos (Basode et al., 2012). No caso específico em estudo, os valores dos polifenóis totais que podem ser usados na prevenção de doenças cardiovasculares, câncer, doenças neurodegenerativas, diabetes ou osteoporose, foram expressivos. A pele de amendoim pode representar uma fonte de baixo custo de fenóis responsáveis pela promoção da saúde, uma vez que é um subproduto utilizado na indústria de amendoim (Yu et al., 2006).

Quanto aos flavonoides, a maior quantidade também é encontrada na amostra com pele, obtendo-se uma diferença média de 2,52 $\mu \mathrm{g} / 100 \mathrm{~g}$ (base úmida). Larrauri et al. (2016) estudaram os extratos de pele de amendoim e observaram valores superiores a $10,74 \pm 0,14 \mu \mathrm{g} / 100 \mathrm{~g}$ b.u para flavonoides totais, relatando nos estudos que as peles de amendoim processadas por diferentes temperaturas e métodos de extração exibem diferentes resultados quanto aos conteúdos fenólicos.

Yu et al. (2005), trabalhando com peles de amendoim cru, encontraram compostos fenólicos semelhantes ao ácido fenólico, como o ácido clorogênico, ácido cafeico e ácido ferúlico. Além destes, flavonoides, incluindo epigalocatequina, epicatequina, galato de catequina, galato de epicatequina e resveratrol, também foram encontrados. 
Os flavonoides são compostos termossensíveis, estão sujeitos a uma maior degradação quando submetidos a altas temperaturas por tempo prolongado. Assim, o método de retirada da pele deve ser criterioso, tendo-se cautela no aquecimento elevado, visto que irá influenciar diretamente na quantidade de compostos antioxidantes do extrato.

\section{Conclusões}

Os extratos aquosos de amendoim com e sem pele mostraram ser uma valiosa alternativa para um melhor aproveitamento do amendoim, proporcionando à população um produto proteico com calorias balanceadas, além de ser uma alternativa para intolerantes à lactose. A bebida acrescida de $1 \%$ de pele enriqueceu o produto quanto ao seu potencial antioxidante devido ao aumento significativo das concentrações de compostos fenólicos totais e de flavonoides.

\section{Agradecimentos}

À Faculdade de Medicina de Olinda, ao Centro Universitário Unifacisa e ao Centro de Tecnologia e Recursos Naturais da Universidade Federal de Campina Grande pelas instalações e pelo apoio durante toda a pesquisa.

\section{Referências}

Abreu, C. R. A., Pinheiro, A. M., Maia, G. A., Carvalho, J. M., \& Sousa, P. H. M. (2007). Avaliação química e físico-química de bebidas de soja com frutas tropicais. Revista Alimentos e Nutrição, 18(3), 291-296. Recuperado em 11 de dezembro, 2019, de http://serv-bib.fcfar.unesp.br/seer/index.php/alimentos/article/viewFile/166/174

Alves, N. M. C., \& Almeida, F. A. C. (2016). Obtenção de extrato aquoso de amendoim "leite de amendoim". In F. A. C. Almeida, J. J. S. Barros Neto, E. M. B. Albuquerque \& B. A. Melo (Eds.), Tecnologias desenvolvidas para o aproveitamento do amendoim. Campina Grande: A Barriguda/AREPB.

Alves, N. M. C., Almeida, F. A. C., \& Albuquerque, E. M. B. (2016). Elaboração de duas bebidas a base de extrato de amendoim e polpa de frutas. In F. A. C. Almeida, J. J. S. Barros Neto, E. M. B. Albuquerque \& B. A. Melo (Eds.), Tecnologias desenvolvidas para o aproveitamento do amendoim (27 p.). Campina Grande: A Barriguda/AREPB.

Anderson, J. W., Baird, P., Davis Junior, R. H., Ferreri, S., Knudtson, M., Koraym, A., Waters, V., \& Williams, C. L.. (2009). Health benefits of dietary fiber. Nutrition Reviews, 67(4), 188-205. PMid:19335713. http://dx.doi.org/10.1111/j.17534887.2009.00189.x

Attree, R., Du, B. \& Xu, B. (2015). Distribution of phenolic compounds in seed coat and cotyledon, and their contribution to antioxidant capacities of red and black seed coat peanuts (Arachis hypogaea L.). Industrial Crops and Products, 67(2), 448-456. http://dx.doi.org/10.1016/j.indcrop.2015.01.080

Basode, R. R., Randolph, P., Hurley, S., \& Ahmedna, M. (2012). Evaluation of hypolipidemic effects of peanut skin-derived polyphenols in rats on Western-diet. Food Chemistry, 135(1), 1659-1666. https://doi.org/10.1016/j.foodchem.2012.06.034

Bicudo, M. O. P., Vasques, E. C., Zuim, D. R., \& Candido, L. M. B. (2012). Elaboração e caracterização de bebida fermentada à base de extrato hidrossolúvel de quinoa com polpa de frutas. B. CEPPA, 30(1), 19-26.

http://dx.doi.org/10.5380/cep.v30i1.28468

Bligh, E. G., \& Dyer, W. J. A. (1959). Rapid method of total lipid extraction and purification. Canadian Journal of Biochemistry and Physiology, 37(8), 911-917. PMid:13671378. http://dx.doi.org/10.1139/o59-099

Chandra, S., \& Gonzalez de Mejia, E. (2004). Polyphenolic compounds, antioxidant capacity, and quinone reductase activity of an aqueous extract of ardisia compressa in comparison to mate (llex paraguariensis) and green (Camellia sinensis) Teas. Journal of Agricultural and Food Chemistry, 52(11), 3583-3589. PMid:15161234. http://dx.doi.org/10.1021/if0352632

Duong, N. D., Qin, J. G., Harris, J. O., Hoang, T. H., Bansemer, M. S., Currie, K.-L., Phan-Thien, K.-Y., Dowell, A., \& Stone, D. A. J. (2016). Effects of dietary grape seed extract, green tea extract, peanut extract and vitamin $C$ supplementation on metabolism and survival of greenlip abalone (Haliotislaevigata Donovan) cultured at high temperature. Aquaculture (Amsterdam, Netherlands), 464, 364-373. http://dx.doi.org/10.1016/..aquaculture.2016.07.011

Fabiansson, S. U. (2014). Safety of food and beverages: safety consideration in developing functional foods (422 p.) In Y. Motarjemi. Encyclopedia of food safety. Castlecrag, USA: Elsevier. http://dx.doi.org/10.1016/B978-0-12-378612-8.00302-4.

Francis, F. J. Analysis of anthocyanins. (1982).In P. Markakis. Anthocyanins as food colors (181 p.). New York: Academic Press. http://dx.doi.org/10.1016/B978-0-12-47255-8.50011-1

Garcia Motta, R., Ribeiro Lodete, A., De Souza Araújo Martins, L., Duarte Leite, N., \& Alonso dos Santos, P. (2017). Bebida fermentada a base de soja com sabor de ameixa e suplementada com inulina em substituição ao iogurte tradicional. Revista Veterinária e Zootecnia, 24(4), 724-733. http://dx.doi.org/10.35172/rvz.2017.v24.243 
Instituto Adolfo Lutz - IAL. (2008). Métodos físico-químicos para análise de alimentos. São Paulo: IAL. Recuperado em 11 de dezembro, 2019,de http://www.ial.sp.gov.br/index/html

Krumreich, F. D., Sousa, C. T., Corrêa, A. P. A., Krolow, A. C. R., \& Zambiasi, R. C. (2013). Teor de cinzas em acessos de abóboras (Cucurbita Máxima L.) do Rio Grande do Sul. In Anais do $8^{\circ}$ Simpósio de Alimentos. Passo Fundo: Universidade de Passo Fundo.

Larrauri, M., Zunino, M. P., Zygadlo, J. A., Grosso, N. R., \& Nepote, V. (2016). Chemical characterization and antioxidant properties of fractions separated from extract of peanut skin derived from different industrial processes. Industrial Crops and Products, 94, 964-971. http://dx.doi.org/10.1016/j.indcrop.2016.09.066

Maia, M. J. L., Rossi, E. A., \& Carvalho, M. R. B. (2006). Qualidade e rendimento do "leite" de soja da unidade de produção de derivados da soja - Unisoja - FCF-Ar/UNESP. Alimentação e Nutrição Araraquara, 17(1), 65-72. Recuperado em 11 de dezembro, 2019, de https://docplayer.com.br/22211329-Qualidade-e-rendimento-do-leite-de-soja-da-unidade-de-producao-dederivados-da-soja-unisoja-fcf-ar-unesp.html

Munekata, P. E. S., Paseto Fernandes, R. P., de Melo, M. P., Trindade, M. A., \& Lorenzo, J. M. (2016). Influence of peanut skin extract on shelf-life of sheep patties. Asian Pacific Journal of Tropical Biomedicine, 6(7), 586-596. http://dx.doi.org/10.1016/j.apjtb.2016.05.002

Oliveira, T. K. B., Almeida, F. A. C., Castro, D. S., Nunes, J. S., \& Ramos, K. R. L. P. (2014). Analise físico-química do extrato aquoso do amendoim. Revista Verde, 9(2), 121-124. Recuperado em 11 de dezembro de 2019, de https://www.gvaa.com.br/revista/index.php/RVADS/article/view/2684/2176

Oliveira, T. K. B., Almeida, F. A. C., Falcão, M. P. M. M., Lemos-Jordão, A. J. J. M., Ramos, K. R. L. P., \& Silva, J. F. (2016). Análise do extrato aquoso de Arachis hipoagea L. no combate à dislipidemia e ao ganho ponderal de ratos wistar submetidos à dieta hiperlipídica. Pesq. Vet. Bras., 36(1), 1121-1126. http://dx.doi.org/10.1590/s0100-736x2016001100011.

Pretti, T., \& Carvalho, M. R. B. (2012). Tecnologia para produção de extrato aquoso de amendoim. Alimentação e Nutrição Araraquara, 23(1), 39-44. Recuperado em 11 de dezembro, 2019, de http://servbib.fcfar.unesp.br/seer/index.php/alimentos/article/download/1333/1195

Shin, G. H., Kim, J. T., \& Park, H. J. (2015). Recent developments in nano formulations of lipophilic functional foods. Trends in Food Science \& Technology, 46(1), 144-157. http://dx.doi.org/10.1016/j.tifs.2015.07.005

Silva, F. A. S., \& Azevedo, C. A. V. (2009). Principal components analysis in the software assistat-statistical attendance. In: World Congress on Computers in Agriculture: Vol. 7. Reno: American Society of Agricultural and Biological Engineers.

Tedesco, M. P., Monaco-Lourenço, C. A., \& Carvalho, R. A. (2017). Characterization of oral disintegrating film of peanut skin extract Potential route for buccal delivery of phenolic compounds. International Journal of Biological Macromolecules, 97, 418425. PMid:28093333. http://dx.doi.org/10.1016/j.ijbiomac.2017.01.044

Universidade Estadual de Campinas - UNICAMP. (2011). Tabela Brasileira de Composição de Alimentos - TACO (4. ed.). Campinas: UNICAMP/NEPA.

Yu, J., Ahmedna, M., \& Goktepe, I. (2005). Effects of processing methods and extraction solvents on concentration and antioxidant activity of peanut skin phenolics. Food Chemistry, 90(1-2), 199-206. http://dx.doi.org/10.1016/j.foodchem.2004.03.048

Yu, J., Ahmedna, M., Goktepe, I., \& Dai, J. (2006). Peanut skin procyanidins: composition and antioxidant activities as affect end by processing. Journal of Food Composition and Analysis, 19(4), 364-371. http://dx.doi.org/10.1016/j.jfca.2005.08.003

Funding: Coordenação de Aperfeiçoamento de Pessoal de Nível Superior - CAPES.

Received: Dec. 12, 2019; Accepted: Dec. 07, 2020 